\title{
Static analysis of adhesively bonded anchorages for CFRP tendons
}

\author{
F. Puigvert ${ }^{\mathrm{a}}$, A.D. Crocombe ${ }^{*}$, L. Gil ${ }^{\mathrm{a}}$ \\ ${ }^{a}$ Department of Strength of Materials and Structural Engineering (RMEE), Polytechnic \\ University of Catalonia, Terrassa, 08222, Spain. \\ ${ }^{\mathrm{b}}$ Faculty of Engineering and Physical Sciences (J5), University of Surrey, Guildford, Surrey GU2 7XH, UK.
}

\begin{abstract}
In pre-stressed concrete structures, consideration is being given to replacing the steel tendons with CFRP rods. One of the challenges associated with this is to develop a suitable anchorage for the CFRP rods. A bonded anchorage was investigated, where the CFRP is potted in a steel tube using epoxy adhesive. Experimental static tests of different configurations were undertaken with failure occurring in the bond. A set of numerical simulations were carried out with different adhesive material models to investigate the static response of the bonded anchorage and its failure mechanism. The adhesive was modelled with linear elastic properties, von Mises plasticity, Drucker-Prager plasticity and progressive damage. A cohesive zone model with progressive damage in the bonded joint was found to be in reasonable agreement with the experimentally recorded data. Also, an analytical formulation was developed (and validated) in order to provide an approximate distribution of shear stress in the bonded joint for circular anchors for adhesives with mainly elastic behaviour.
\end{abstract}

Keywords: Adhesively bonded joints, CZM, FEM analysis, CFRP rods and potted anchor.

\section{INTRODUCTION}

One of the causes of deterioration of pre-stressed concrete structures is the corrosion of the steel reinforcement. It depends on the environment, the protection of the reinforcement and the thickness of the concrete cover. In reality, the reinforcement suffers corrosion and it may weaken the mechanical properties of the material. Therefore, in large infrastructures such as bridges, there are maintenance campaigns that renew and repair the concrete cover and replace the steel tendons.

Use of Fibre Reinforced Polymer (FRP) composite materials is common in the aeronautical and naval sectors. The employment of these materials is increasing in civil construction due to their high mechanical properties, light weight and, perhaps most importantly, their high resistance to corrosion. In some applications where corrosion protection for reinforcement becomes very expensive, the use of tendons of composite materials provides a reasonable alternative.

The FRP fibres most used in this sort of application are carbon, glass and aramid. The choice of the proper fibre is based on cost, strength, stiffness and durability. Nonetheless, there are many different products for each kind of fibre. The matrix of the composite material is usually a thermoset polymer, and the most common are polyester, vinylester, epoxy, phenolic and polyurethane. The formulation and physicochemical properties of these resins are practically unlimited. In addition, composite materials are heterogeneous and anisotropic. The mechanical properties of a composite material depend on the properties of fibre and matrix, as well as the manufacturing process.

Whilst glass and aramid tendons show a lower longitudinal tensile strength than pre-stressed steel tendons, carbon tendons are $20-50 \%$ stronger. Also, the elastic moduli of glass and aramid tendons are three times lower than steel tendons while carbon tendons have a modulus only

\footnotetext{
Corresponding author. Tel.: +44-1483-689-194; fax: +44-1483-306-039.

E-mail address: a.crocombe@surrey.ac.uk (A.D. Crocombe).
} 
slightly lower than the steel. However, unlike steel tendons, FRP tendons have a linear elastic response until failure. According to the American Concrete Institute (ACI) [1], CFRP can develop the same mechanical properties as the steel when used to prestress concrete structures. In addition, the research of Mertol et al. [2] showed that CFRP tendons are a durable option in the design of structures for use in aggressive environments.

Even though these composite materials have excellent properties for use in pre-stressed structures, research into the anchoring system is still required. Due to the low transverse mechanical properties of the FRP rods, the common mechanical anchorage cannot be used [3]. Furthermore, an anchoring system based on holes and bolts would generate a stress concentration which could damage the joint [4]. Also, Jones [5] indicated the non-uniform stress distribution around the hole may cause a premature failure. For this reason, two main anchor systems for composite materials are generally considered: mechanical anchors and adhesively bonded anchors.

Mechanical anchors for FRP tendons are based on the current mechanical anchor with several modifications. They consist in a barrel housing which uses several wedges to grip the tendon. Current anchoring systems have hardened teeth to increase the load transfer. In systems with composite materials, these teeth must be removed due to the damage they would induce in the FRP tendon. The conical shape of the barrel and wedges must develop enough friction to transfer the load properly from the tendon to the anchor. However, these wedge anchors generate a high radial pressure. These wedges tend to dig into the surface of the tendon causing premature failure in the area of the anchor as mentioned by Schmidt et al. [3]. Nanni et al. [6] studied the behaviour of the mechanical anchor for composite bars. It was found that a higher value of load can be reached when a material with a lower elastic modulus was used in the interface between the composite rod and the wedges. In that case, the local damage was produced in this material. Recently, the work of Schmidt et al. [7] collected the latest developments concerning mechanical anchors for composite materials. The researchers studied different configurations of the components mentioned previously. Also, the anchor was assessed through the finite element method achieving good agreement with the experimental load-displacement data. Their study concluded that the current mechanical anchor for FRP tendons does not allow the maximum strength of the tendons to be developed.

On the other hand, an adhesive bond-type anchorage consists of a steel housing inside which single or multiple rods are bonded with a resin, usually epoxy. The performance of a bond-type anchorage depends mainly on the geometry and bond length of the tendon, the properties of the epoxy resin, and the dimensions of the steel housing. Also, joints with adhesives allow easy handling and accurate adjustment of the products. Furthermore, bond-type anchorages have a somewhat more uniform stress distribution than mechanical anchors. For this reason, adhesively bonded joints generally show higher efficiencies with FRP materials as indicated by Bahei-ElDin and Dvorak [8].

Nanni et al. [6] also studied the behaviour of tubular adhesive anchors. The researchers used different composite tendons and adhesives in their work. All the anchors were tensioned until failure occurred (at the adhesive-tendon interface). The maximum load achieved was lower than the maximum load capacity of the tendons. Pincheira and Woyak [9] found that the optimal bond length was 50 times the diameter of the FRP tendon. With this consideration, the failure should occur in the FRP tendon as it would reach the maximum value of tensile strength. However, this depends on the mechanical properties of the material used.

Many researchers have observed that the failure in adhesively bonded joints for composite materials occurs in or around the composite-adhesive interface. Thus, researchers have focused on the analysis of the stresses in the adhesive bonded length. Völkersen [10] was the first to study the shear stress distribution in double lap joints. Völkersen's analysis considers the 
adhesive to be deformed by shear stress and the substrates by tension. The highest shear stress occurs at the ends of the joint and is lowest in the centre. This analysis is adequate for double lap joints but does not include the effect of substrate bending moment caused by the eccentric loading that is more dominant in single lap joints. Subsequently, Goland and Reissner [11] considered bending and transverse loads, as well as axial loads, in the substrate. Later, Tsai et al. [12] incorporated shear strains in the substrates, which was shown to be more appropriate for composites. Hart-Smith [13], developed Völkersen's analysis for double lap joints and GolandReissner's analysis for single lap joints by including plasticity in the adhesive. Da Silva et al. [14][15] have collected and compared many of these analytical approaches.

More advanced analyses have been carried out using the finite element method which enables adhesive and substrate non-linearities, progressive damage and coupled hygro-mechano-thermal effects to be included [16][17]. However, the formulations discussed above are for plane geometry bonded joints. These need to be extended to accommodate circular geometries such as the anchors being considered in this work. There are many theoretical models [18][19] regarding the pull-out of fibres in the literature based on either fracture energy or shear stress analysis, but these models are developed to understand the mechanics of the debonding process of a single fibre from a brittle matrix.

Although many static experimental joint tests have been undertaken, little attention has been paid to the failure mechanism of the potted anchor and its numerical modelling using the finite element method. For this reason, in this paper a set of static experimental tests of a CFRP anchor potted with epoxy adhesive in a steel tube housing with different geometries were undertaken and the results compared with different numerical models. In addition, the analytical formulation outlined in [12] has been developed to be used in circular adhesive joints. The external surface of one of the anchors was instrumented with strain gages to validate the analytical formulation presented.

\section{EXPERIMENTAL WORK}

The $8 \mathrm{~mm}$ diameter carbon fibre/epoxy resin rods used in this study were manufactured using a pultrusion process. The contents of fibre and resin are $65 \%$ and $35 \%$ by volume, respectively. The rods contain shallow depressions on the surface in order to improve the bond with the adhesive. The tensile strength of the rod is $2500 \mathrm{MPa}$ and the modulus of elasticity is $140 \mathrm{GPa}$. The adhesive used was MBrace Primer, a low viscosity polyamine cured epoxy manufactured by BASF Chemical Company. The modulus of elasticity of the adhesive is $700 \mathrm{MPa}$. The tensile and compressive yield stresses are 14.5 and 26.2 MPa respectively [20].

The CFRP rods were potted in steel housings using the epoxy resin. The inner surface of the steel housing was prepared before attaching the tendon using a solvent to remove any impurities. The CFRP rods are provided with a peel ply that must be removed immediately prior to bonding. No other preparation of the CFRP rods was required. The anchors were cured at room temperature, according to the specifications of the company. The geometries of all configurations are summarised in Figure 1 and Table 1. The parameters assessed include the bonded length and the potting adhesive thickness.

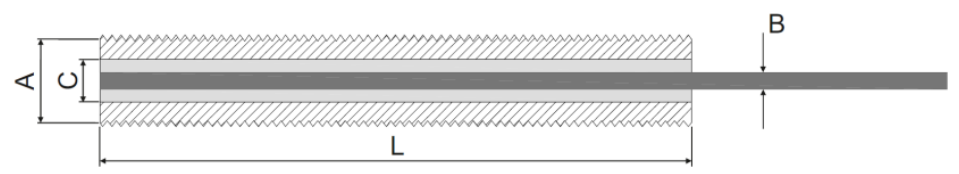

Figure 1. Dimensional details of the anchors.

One specimen was instrumented with eight strain gauges bonded onto the outside of the steel housing in order to validate the analytical formulation developed. The strain gauges used in this research had a gauge length of $1 \mathrm{~mm}$ and a resistance of $350 \Omega$. The surface beneath the gauges 
was prepared before attaching the gauges using an abrasive paper (grade 220) and M-Prep Conditioner A immediately followed by M-Prep Neutralizer 5A from Vishay. Then, the gauges were bonded on the prepared area using a cyanoacrylate adhesive M-bond 200.

Table 1. Geometric characteristics of anchorage.

\begin{tabular}{ccccc}
\hline Specimen & $\begin{array}{c}\text { Steel tube } \\
\text { outer } \\
\text { diameter, A } \\
{[\mathrm{mm}]}\end{array}$ & $\begin{array}{c}\text { CFRP rod } \\
\text { diameter, } \\
\text { B [mm] }\end{array}$ & $\begin{array}{c}\text { Steel tube } \\
\text { bore, C } \\
{[\mathrm{mm}]}\end{array}$ & $\begin{array}{c}\text { Anchor } \\
\text { length, } \\
\text { L [mm] }\end{array}$ \\
\hline 14_200mm_1 & 26 & 8 & 14 & 200 \\
14_200mm_2 & 26 & 8 & 14 & 200 \\
14_200mm_3 & 26 & 8 & 14 & 200 \\
20_200mm_1 & 26 & 8 & 20 & 200 \\
24_200mm_1 & 30 & 8 & 24 & 200 \\
14_460mm_1 & 26 & 8 & 14 & 460
\end{tabular}

Table 2.Summary of experimental test and predicted results.

\begin{tabular}{ccc}
\hline Specimen & $\begin{array}{c}\text { Experimen } \\
\text { tal failure } \\
\text { load }[\mathrm{kN}]\end{array}$ & $\begin{array}{c}\text { Predicted } \\
\text { failure } \\
\text { load }[\mathrm{kN}]\end{array}$ \\
\hline 14_200mm_1 & 58.70 & 60.24 \\
14_200mm_2 & 60.20 & 60.24 \\
14_200mm_3 & 64.97 & 60.24 \\
20_200mm_1 & 75.10 & 70.46 \\
24_200mm_1 & 87.24 & 73.86 \\
14_460mm_1 & 110.70 & 110.66 \\
\hline
\end{tabular}

Pull-out tests on the anchor models based on the ACI 440.3R-04 B.10 [21] were carried out using an MTS actuator. All specimens were tested in tension to failure under displacement control, at $1 \mathrm{~mm} / \mathrm{min}$. The load, displacement and strain data were recorded at a frequency of 50 $\mathrm{Hz}$ using an MGCPlus data acquisition system. The pullout test specimens, without and with strain gauges, are shown in Figure 2. The casings had external threads which were used to attach the specimens to the test machine.

In all the specimens the failure occurred in the adhesive but very close to the interface between the adhesive and the CFRP rod. Figure 3 shows the typical failure phenomenon throughout the bond length.

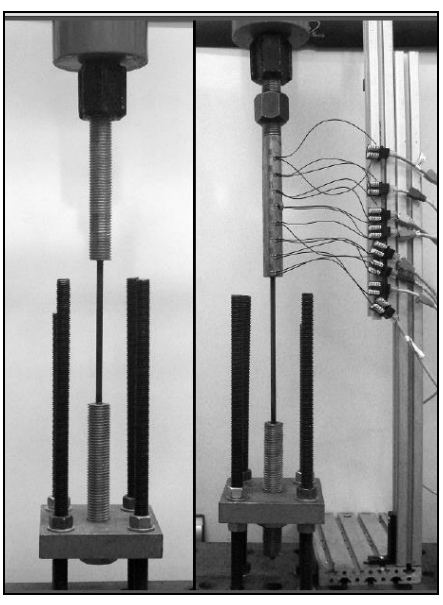

Figure 2. Test setup of specimens with epoxy bonded anchorage.

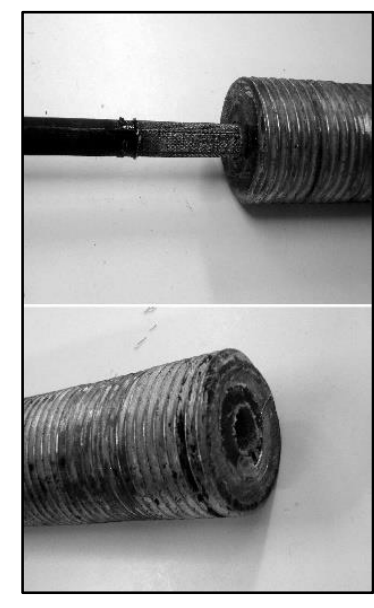

Figure 3. Typical failure surfaces in the bonded anchorages.

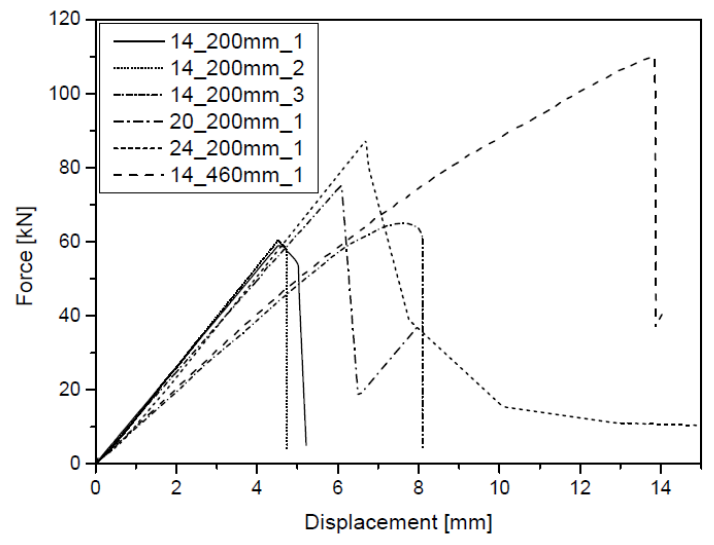

Figure 4. Measured load and displacement response of all the specimens with epoxy-bonded anchorage.

As shown in Figure 4, force-displacement curves were largely linear up to the point of failure, which occurred suddenly. However, on some curves there was a slight change in the slope. This might be due to yielding or damage of the adhesive. It can be noted that the specimens with higher adhesive thickness achieved a higher ultimate force (see Table 2). A reason for this might be that a more uniform distribution of adhesive stress occurred with the thicker adhesive layers. Furthermore, with the same adhesive thickness a higher ultimate force was reached with the longer bonded joint. This is probably due to the fact that there is more load carrying area of the adhesive in the longer joints.

\section{ANALYTICAL MODELLING}

The equilibrium equations of [12] were modified in order to take into account the circular geometry of the anchor. A linear constitutive equation of the materials involved was considered. Also, a linear shear distribution through the thickness of the substrates was assumed. 
Only an outline of the analysis is presented here, full details are provided elsewhere [22]. Following the nomenclature of Figure 5, the shear stress distribution on the interface between the adhesive and the rod $\tau_{i}$ can be determined through Eqn 1
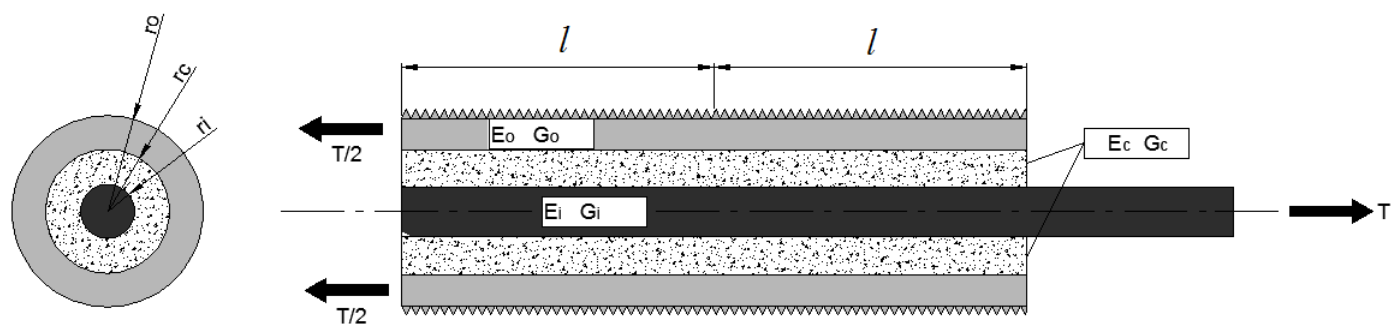

Figure 5. Anchor geometry.

$$
\tau_{i}=A \cdot \sinh (\beta \cdot x)+B \cdot \cosh (\beta \cdot x)
$$

The coefficient $\beta$ is determined by:

$$
\beta^{2}=\frac{\frac{G_{c} \cdot r_{i}}{\left(r_{c}-r_{i}\right)} \cdot\left(\frac{2}{E_{i} \cdot r_{i}^{2}}+\frac{2}{E_{o} \cdot\left(r_{o}^{2}-r_{c}^{2}\right)}\right)}{1+\frac{G_{c}}{\left(r_{c}-r_{i}\right)} \cdot\left[\frac{5 \cdot r_{i}}{12 \cdot G_{i}}+\frac{1}{\left(r_{o}^{2}-r_{c}^{2}\right)} \cdot\left(\frac{r_{i} \cdot\left(r_{o}-r_{c}\right) \cdot\left(r_{o}^{2}-r_{c}^{2}\right)}{2 \cdot G_{o} \cdot r_{o}}-\frac{r_{i} \cdot\left(r_{o}^{4}-r_{c}^{4}\right)}{4 \cdot G_{o} \cdot r_{o} \cdot\left(r_{o}-r_{c}\right)}\right)\right]}
$$

Where $E_{0}$ is the elastic modulus in the longitudinal direction of the steel housing, $E_{i}$ is the elastic modulus in the longitudinal direction of the FRP tendon, $G_{0}$ is the shear modulus in the longitudinal direction of the steel housing, $G_{i}$ is the shear modulus in the longitudinal direction of the FRP tendon and $G_{c}$ is the shear modulus in the longitudinal direction of the adhesive layer. The coefficients $A$ and $B$ for a 'Pull-Pull' solution are determined by:

$$
A=\frac{\beta \cdot l \cdot \tau_{m i}}{\cosh (\beta \cdot l)} \cdot\left(\frac{1-\frac{E_{i} \cdot r_{i}^{2}}{E_{o} \cdot\left(r_{o}^{2}-r_{c}^{2}\right)}}{1+\frac{E_{i} \cdot r_{i}^{2}}{E_{o} \cdot\left(r_{o}^{2}-r_{c}^{2}\right)}}\right) \quad \text { (3) } B=\frac{\beta \cdot l \cdot \tau_{m i}}{\sinh (\beta \cdot l)}
$$

Here $\tau_{m i}$ is the average shear stress on the adhesive-CFRP interface and is defined by Eqn. 5;

$$
\tau_{m i}=\frac{T}{2 \cdot \pi \cdot r_{i} \cdot 2 \cdot l}
$$

It should be noted that this formulation assumes that the adhesive behaves as a linear elastic material. The adhesive used in the experimental tests is ductile and it is likely that a plastic zone may develop before final failure. Thus the analytical formulation was validated at lower levels of load for the specimen 24_200mm_1, which was instrumented with strain gauges on the outer steel tube (adapted to introduce a region with no thread) for this purpose.

Considering the axial stresses in the steel housing and the steel constitutive equation, the analytical formulation for the shear stress on the adhesive-tube interface can be used to find the normal strain in the steel housing (assumed constant across the wall thickness). This was compared with the experimental recorded data at low values of load where the adhesive remained within its linear region. Figure 6 compares the experimental and analytical strains 
along the external surface of the anchor. As can be seen the correlation between the two are good, thus validating this analysis at lower loads.

In addition, the analytical solution was used to predict the shear stress distribution at the adhesive-rod interface for the four geometries at their respective experimental failure load. As anticipated, the maximum shear stresses developed were considerably in excess of the yield stress for the adhesive, given the Experimental section above. However, it can be seen that the maximum shear stress predicted was common for all the configurations with the same anchor length independent of the adhesive thickness. Thus, in principle, it might be possible to use the analytical solution to predict the failure load of the anchor for different thickness. However the failure stress would have no physical significance. Further, this would not be applicable for different anchor lengths as it can be seen in Figure 7 that using this elastic analysis a higher "adhesive failure stress" is required for a longer anchor length where the bond length refers to the adhesive-rod interface bond from the loading end of the anchor to the bottom of the anchor. In practice it is likely that yielding occurs and that the longer anchor length enables a longer yield zone to be developed so producing higher joint strengths. To investigate this further and model some of these more complex aspects it is necessary to undertake FE modelling and this is discussed in the next section. Also, the solution developed was found to be in a very good agreement with the linear analysis carried out with finite element method, which is presented in the next section (see Figure 9).

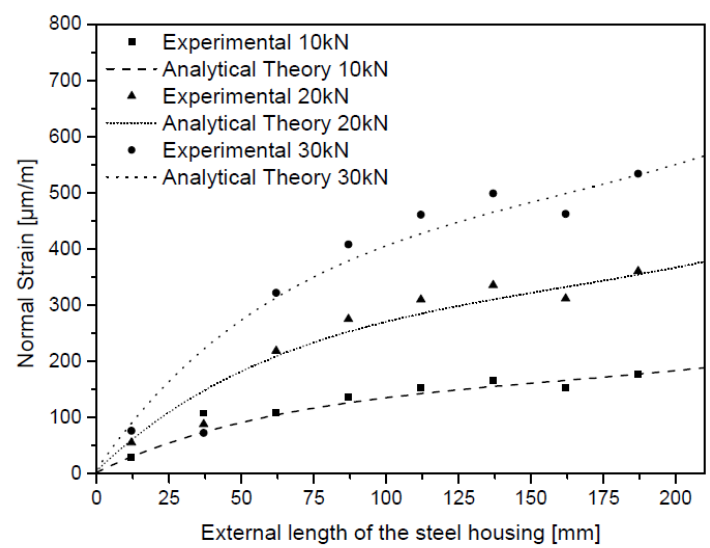

Figure 6. Normal stress distribution along the external surface of the steel housing of the specimen 24_200mm_1 at different loads.

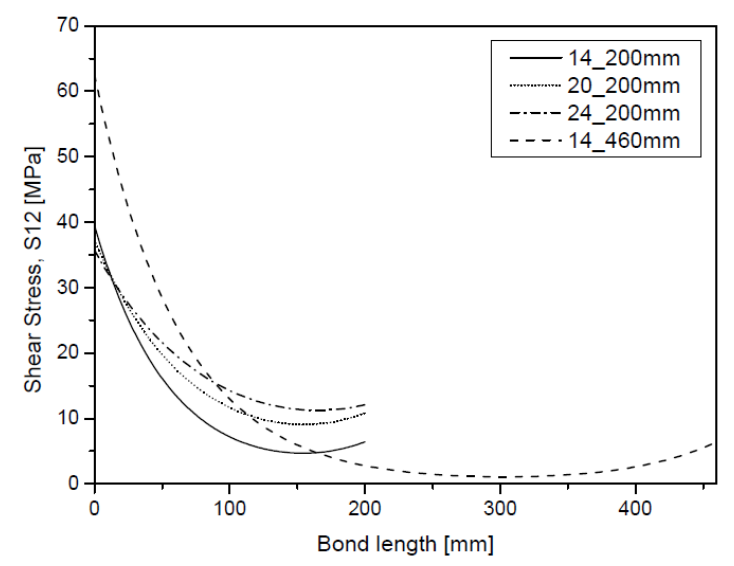

Figure 7. Shear stress distribution along the adhesive-rod interface obtained with the analytical formulation.

\section{NUMERICAL MODELLING}

In order to predict the static response of the bonded anchorage, a finite element model was developed in Abaqus/CAE. Owing to the shape of the anchor, a 2D axisymmetric model was used (see Figure 8). This simplified the model and hence optimised computing resources. Four different geometries were modelled according to the geometries tested experimentally (see Table 1). The bottom of the steel housing was fully fixed and the top of the CFRP rod was loaded either with an axial force or an axial displacement. Different material models of increasing complexity were investigated. Initially the adhesive was modelled with linear elastic properties. Following this adhesive yielding was modelled using both von Mises plasticity and DruckerPrager plasticity, the latter enabling the hydrostatic dependency of the adhesive to be included in the modelling. Finally, progressive damage was included in the modelling in order to capture the entire mechanical response of the anchor including the damage initiation and evolution leading to joint failure. Progressive damage modelling with a cohesive zone was investigated where the elements followed a traction separation model. The remainder of this paper contains a more detailed discussion on a number of these aspects. Geometric non-linearity was included in all the analyses. Four-noded axisymmetric stress elements (CAX4R) with a mesh density of $0.5 \mathrm{~mm}$ 
were used for the whole model. When a cohesive zone was used, four-node axisymmetric cohesive elements (COHAX4) with a tri-linear traction-separation response were utilised to study the progressive damage in the adhesive bond line. The size of the cohesive element was $0.5 \times 0.5 \mathrm{~mm}$ throughout the adhesive bond line.

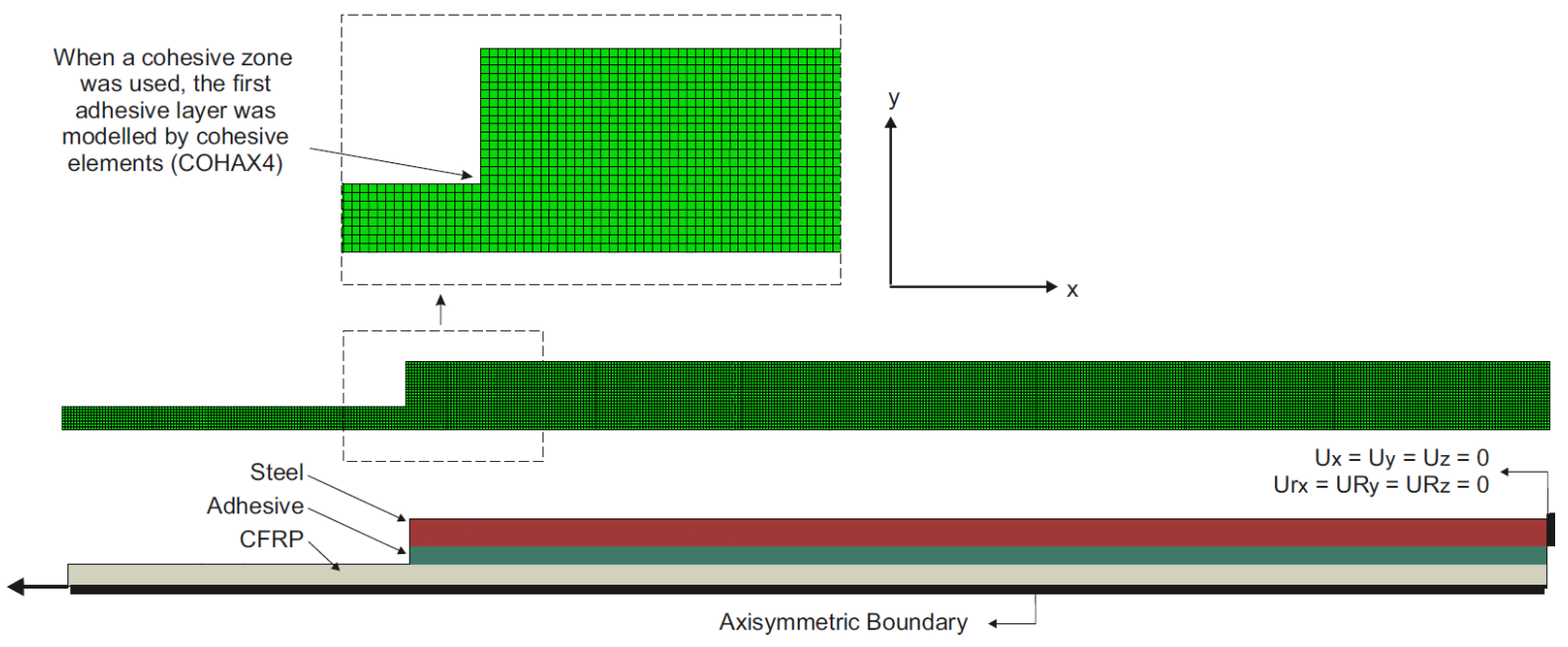

Figure 8 . Finite element mesh and boundary conditions for the geometry with a bore and length of 14 and 200 mm respectively.

Table 3. Mechanical properties of the materials involved in the numerical modelling.

\begin{tabular}{cccc}
\hline Parameters & $\begin{array}{c}\text { Steel } \\
\text { tube }\end{array}$ & $\begin{array}{c}\text { CFRP } \\
\text { rod }\end{array}$ & Adhesive \\
\hline$v[-]$ & 0.3 & 0.2 & 0.425 \\
E $[\mathrm{MPa}]$ & 200,000 & 141,000 & 700 \\
\hline
\end{tabular}

Table 4. Tensile and compressive data of the bulk adhesive.

\begin{tabular}{ccccc}
\hline Properties & $\begin{array}{c}\text { Yield } \\
\text { strength } \\
{[\mathrm{MPa}]}\end{array}$ & $\begin{array}{c}\text { Strain at } \\
\text { yield } \\
{[\%]}\end{array}$ & $\begin{array}{c}\text { Ultimate } \\
\text { Strength } \\
{[\mathrm{MPa}]}\end{array}$ & $\begin{array}{c}\text { Rupture } \\
\text { strain } \\
{[\%]}\end{array}$ \\
\hline Tensile & 14.5 & 2.0 & 17.2 & 40 \\
Compressive & 26.2 & 4.0 & 28.3 & 10 \\
\hline
\end{tabular}

\subsection{Linear elastic modelling}

Initially a linear elastic analysis was undertaken of all four configurations. The Young's modulus and Poisson's ratio used for each material are presented in Table 3. In these linear elastic analyses the experimental failure load (see Table 2) was applied to the CFRP bar not a displacement. The shear stress distribution along the adhesive-rod interface was assessed at the failure load for all the geometries (see Figure 9).

The results are broadly consistent with and confirm the analytical modelling discussed above (compare Figures 9 and 7). The anchors with the same bonded length but different adhesive thicknesses all reached similar shear stress values when loaded at their respective failure loads even though these were quite different (see Table 2). According to these results, a higher load can be reached for the same level of maximum stress as the adhesive thickness increases (as noted with the analytical solution). However, the linear elastic finite element analyses show a perturbation in the stress at both ends of the adhesive layer due to the end effects. The analytical solution is not able to provide this level of detail. Figure 10 illustrates the shear stress distribution through the different materials at the top of the anchor where stresses are highest. The in-board peak in the adhesive shear stress that gives rise to the perturbation discussed above and seen in Figure 9 is clearly seen in this more localised view. However, although the maximum adhesive stresses at the failure load are the same for all three anchors of the same length there are two main problems. The first is that this value is not the same for the longer anchor and the second is that these maximum stresses are well in excess $(>40 \%)$ of the yield stresses provided by the manufacturer for this adhesive (see Table 4). Both factors would suggest that the behaviour of the adhesive cannot be modelled as linear elastic. The adhesive is quite 
ductile and clearly there will be considerable yielding in the joint prior to failure. Consequently, further analyses were carried out considering non-linear behaviour of the adhesive. From the linear analyses it was clear that stress levels in the CFRP rod and steel were not sufficiently high to cause yielding in these materials and hence linear elastic models were retained for these.

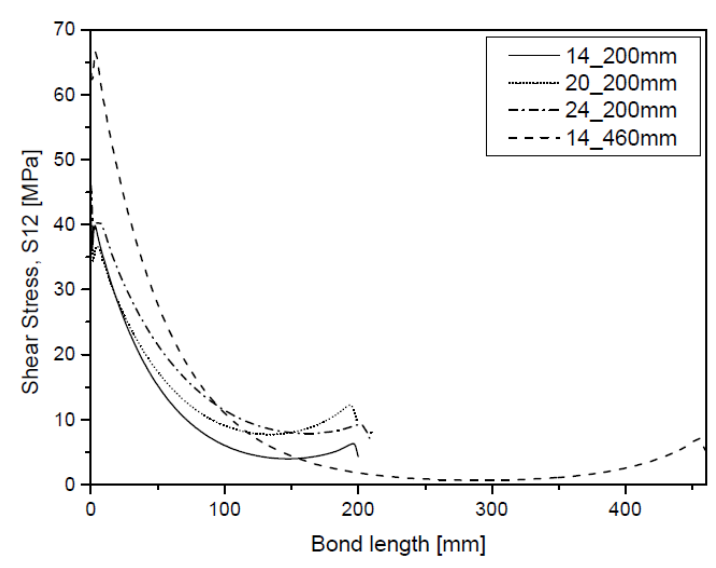

Figure 9. Shear stress distribution along the adhesive-rod interface obtained with lineal elastic modelling.

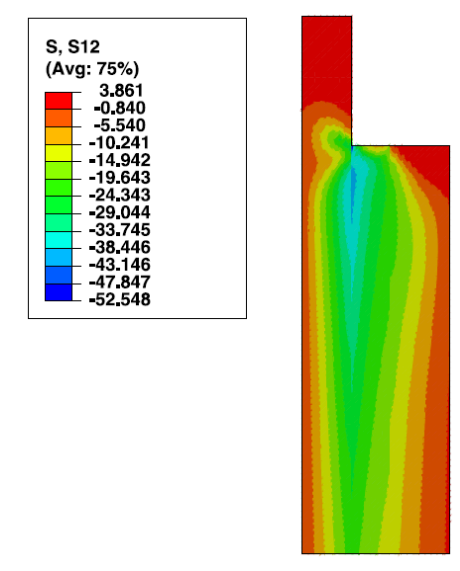

Figure 10. Shear stress distribution at the top of the anchor (MPa).

\subsection{Elasto-plastic modelling}

Initial analyses were elastic-perfectly plastic (ie no strain hardening) assuming von Mises yielding. The analyses were carried out to the experimental failure load for all the geometries for a range of different adhesive yield stresses. When the yield stresses were below a certain (configuration dependent) value the maximum failure load could not be achieved, see Figure 11. This was because at these yield stresses global yielding occurred at loads below the failure load. When selecting a yield stress above these levels the failure load could be achieved but, for a specified yield stress, a different maximum plastic strain (ie a differing extent of yield) was reached in each configuration. The relationship between the maximum plastic strain at failure and the yield stress is presented in Figure 11 for each of the 4 anchor configurations. It is clear that the use of a critical plastic strain to predict the strength of these anchor joints is not possible. Whilst the use of an adhesive thickness dependent failure strain might be feasible it would be difficult to justify physically and also the value of these strains are considerably higher that the stated material data (see Table 4). Furthermore, the mismatch in failure strains for the two anchors that have the same adhesive thickness but different overlap length (see Figure 11) suggest that this approach is wholly inappropriate.

As shown in previous studies [23][24], polymers generally exhibit greater yield stresses in compression than in tension. This is certainly the case for the adhesive used in this work as can be seen in Table 4, which shows the published tensile and compressive data of the bulk adhesive. Therefore, the classical von Mises yield criterion (which has no hydrostatic yield dependency) does not fully model the adhesive. In order to take into account the hydrostatic pressure sensitivity in the adhesive, Drucker-Prager plasticity was considered. The yield criterion for this model was based on the shape of the yield surface in the meridional plane, where the equivalent stress depends on the hydrostatic pressure. The material parameters used in this Drucker-Prager model are summarised in Figure 12 and Table 5. The experimental failure load was applied to each of the four joint configurations and the resulting stress and plastic strain distributions obtained. A plot of the equivalent stress (which is the yield stress for the plastic region) for the anchor with a bore and length of $14 \mathrm{~mm}$ and $200 \mathrm{~mm}$ respectively at its failure load is shown in Figure 13. It can be seen that, unlike the von Mises plasticity, the yield stress varies along the length of the anchor. This is because the hydrostatic pressure varies along the overlap, tending to be highest towards the overlap ends. The equivalent plastic strains corresponding to the failure 
load of each joint are shown in Table 6. It can be seen that the strains are generally lower than those obtained with von Mises plasticity and are more physically reasonable. This is because higher levels of yield stress are sustained due to the hydrostatic pressure. Further, there is less variation between the critical level of strains, suggesting that these would predict the anchor loads better. However, even with this model the loads would not be predicted to better than around $+/-20 \%$.

The fact that an elasto-plastic model with a critical plastic strain was unable to properly explain the effect of anchor length on joint strength suggested that a more complex failure mechanism might be active. Specifically, failure might occur in the higher stressed regions followed by a frictional force resisting separation at the failed surfaces. Such a mechanism would account for the dependency of the strength on anchor length, but in a way that better matched the measured experimental data. To consider this further it was necessary to undertake progressive damage modelling where the material can reach a peak, fail, and then experience further deformation at a reduced level of (frictional) load. This is reported in the next section.

Table 5. Drucker-Prager plasticity parameters.

\begin{tabular}{cc}
\hline \multicolumn{2}{c}{ Drucker-Prager Parameters } \\
\hline Type & Exponent form \\
\hline Material constant $a$ & 0.02849 \\
Exponent $b$ & 2 \\
Dilatation angle, $\psi$ & 24.23 \\
\hline
\end{tabular}

Table 6. The equivalent plastic strains at the experimental failure load.

\begin{tabular}{cc}
\hline Specimen & PEEQ [\%] \\
\hline DIA_14_200mm & 48.2 \\
DIA_20_200mm & 29.1 \\
DIA_24_200mm & 40.5 \\
DIA_14_460mm & 53.6 \\
\hline
\end{tabular}

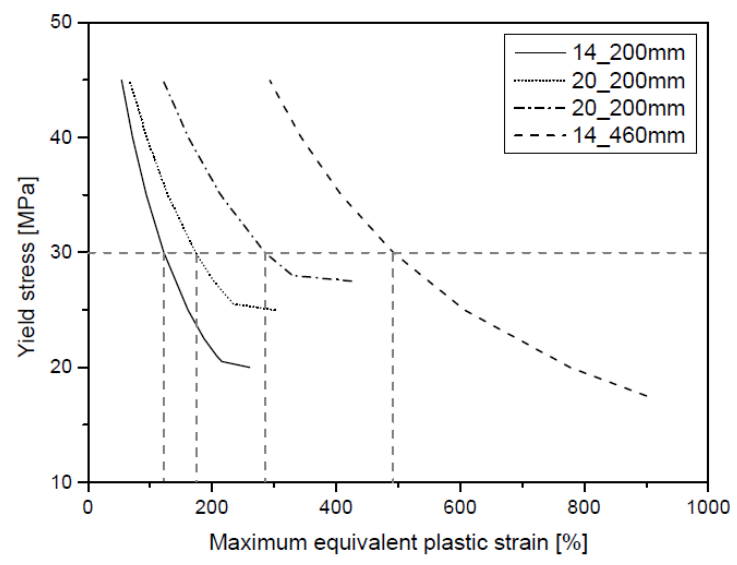

Figure 11. Variation of maximum equivalent plastic strain at failure with yield stress (von Mises plasticity).

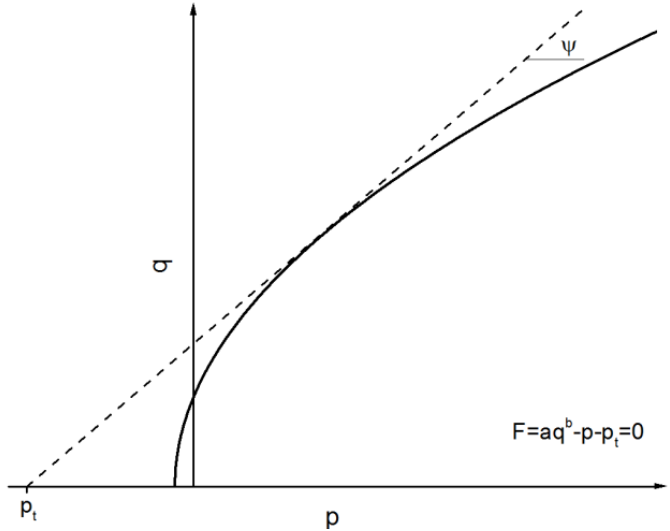

Figure 12. Yield surface in the meridional plane in Drucker-Prager plasticity.

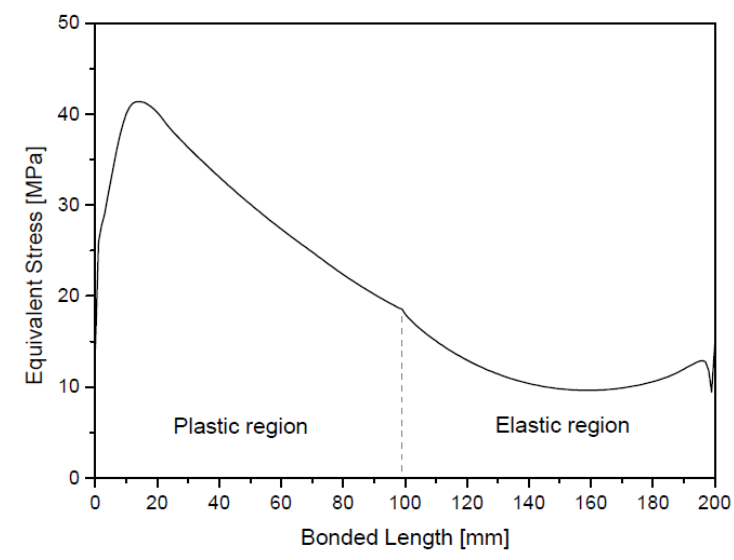

Figure 13. Equivalent stress distribution along the adhesive-rod interface (Drucker-Prager plasticity).

\subsection{Progressive damage modelling}


The adhesive was modelled with a progressive damage model (CZM) where the constitutive behaviour of the cohesive element was defined by a traction-separation response. This is implemented by following the assigned elastic curve until a point of damage initiation. Subsequent to this the stress is modified by a damage parameter than ranges between 0 (no damage) and 1 (fully damaged). There are various ways of defining damage and in this work it was defined as a function of separation to give a sharp drop (to simulate fracture) followed by a long region of constant but high damage (to simulate the friction process). A tri-linear tractionseparation response was utilised to simulate the loading, failure and subsequent (post-failure) friction between both materials. This is illustrated in Figure 14, which shows the resulting traction-separation response calibrated with the experimental results.

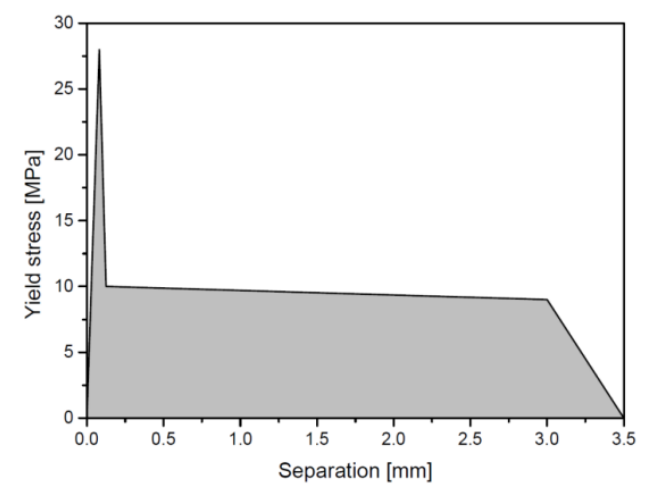

Figure 14. Progressive damage modelling response used in CZM.

When damage was initiated, the maximum stress moved down the adhesive-rod interface. The predicted load-displacement response for each of the four joints is shown in Figure 15 and is discussed in more detail later. Figure 16 shows the shear stress distribution along the CFRP interface at the maximum load reached in each of the geometries (as shown in Figure 15). Damage spreads in from both ends of the bond but mainly from the end where the CFRP is loaded ( $0 \mathrm{~mm}$ bond length in Figure 16). The region where the shear stress is maximum (at about $18 \mathrm{MPa}$ ) indicates the current damage front (ie damage has spread about $150 \mathrm{~mm}$ in the $200 \mathrm{~mm}$ long anchors and about $350 \mathrm{~mm}$ in the $460 \mathrm{~mm}$ long anchor). Material to the left of this front has damaged and to the right is still undamaged (until the other end is approached). The rapid fall in shear stress corresponds with the rapid damage in the traction separation model whilst the plateau lower level corresponds to the friction region. In the shorter anchors the damage has spread furthest in the anchor with the thinnest adhesive layer. As can be seen, the maximum load in each anchor was reached when the maximum stress was close (less than $50 \mathrm{~mm}$ ) to the bottom of the bonded joint. The longer "friction" region in Figure 15 for the $460 \mathrm{~mm}$ long anchor enabled this configuration to sustain the higher failure load observed experimentally.

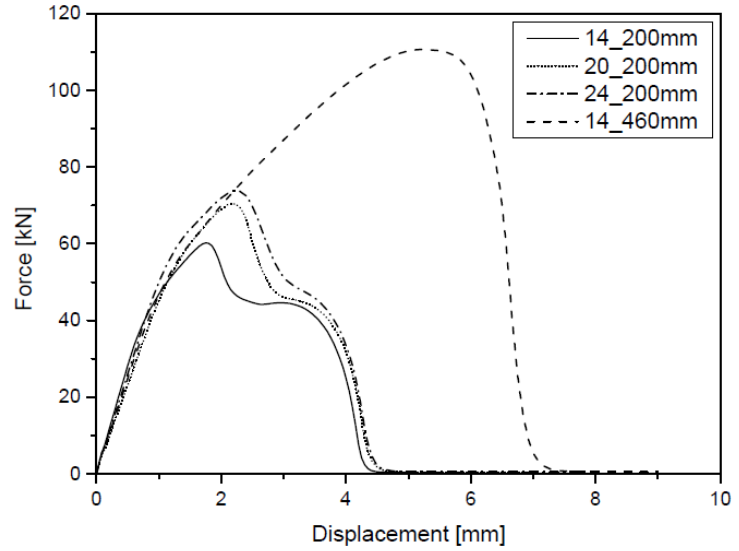

Figure 15. Force - displacement diagram obtained with

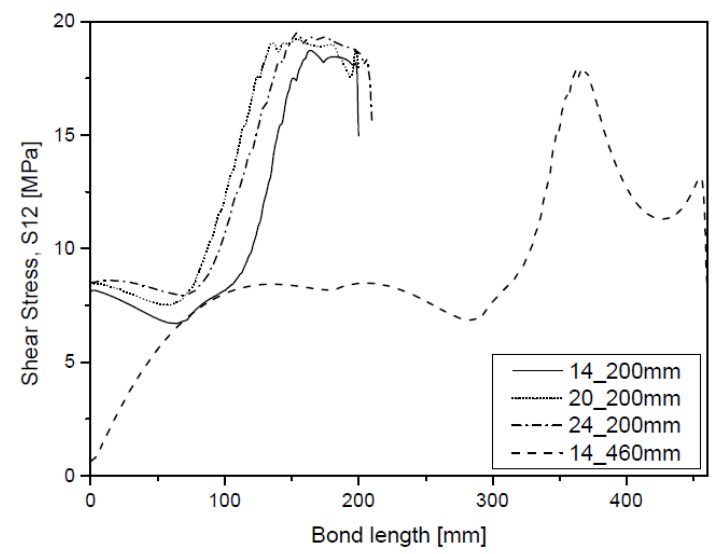

Figure 16. Shear stress distribution along the adhesive-rod 
Figure 17 illustrates three different stages of the damage front evolution and its shear stress distribution in the adhesive section for the anchor with the thickest adhesive. Point "a" shows the shear stress distribution when damage starts at the top of the joint. As can be seen the corresponding force at this stage is slightly greater than $37 \mathrm{kN}$. Below this force the joint behaves completely linearly with the maximum shear stress occurring at the top of the bonded joint. When damage initiates, the maximum shear stress travels along the joint towards the bottom. At the point " $b$ ", the damage front and the maximum values of shear stress have reached around the middle of the joint. It can be noted that the top of the bonded joint is highly damaged with values between 0.9 and 1 . This damage zone is transmitting the lower frictional loads. Finally, point "c" shows the shear stress distribution in the adhesive when the joint reaches the maximum damage it can sustain. The force at this stage is very close to the failure load. The maximum values of shear stress occur at the bottom of the joint and most of the joint is in the frictional region.
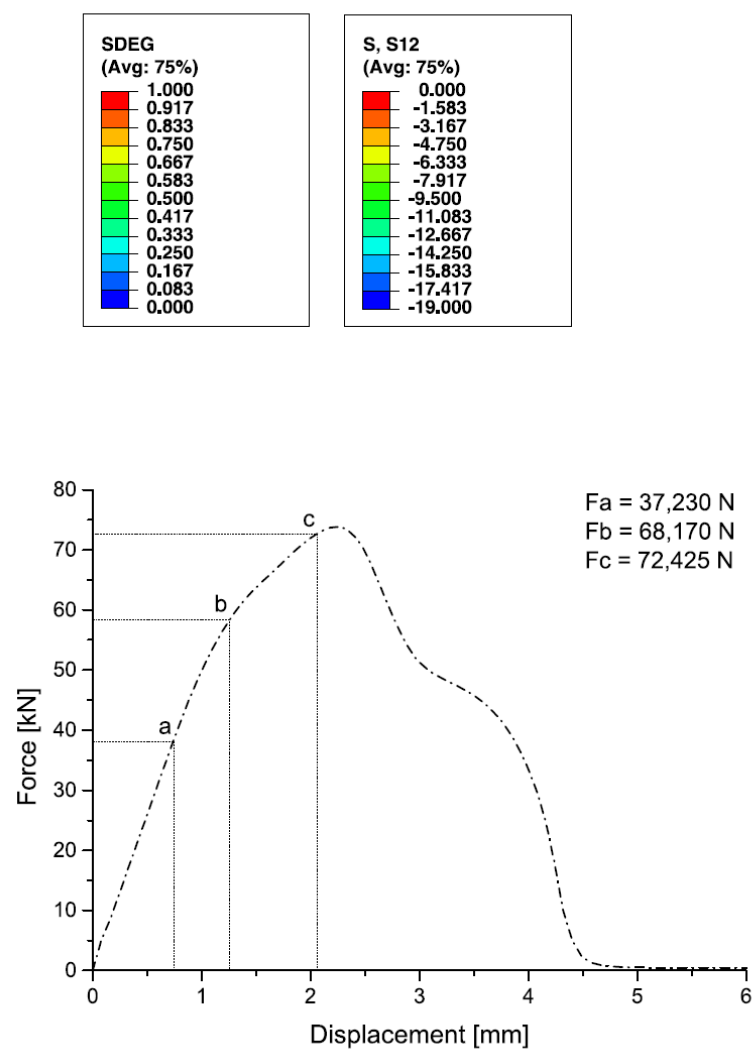
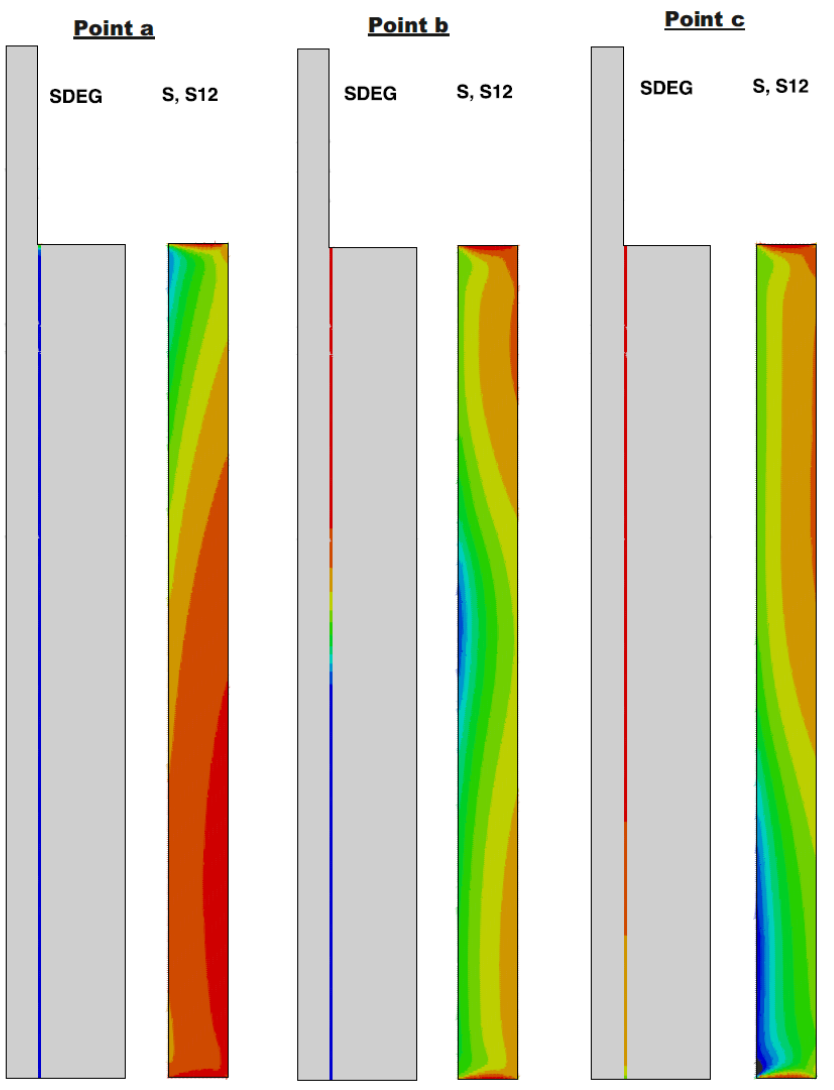

Figure 17. Damage and shear stress evolution along the cohesive layer and adhesive section respectively for the geometry DIA_24_200mm.

Returning to considered the predicted failure loads in Figure 15, as discussed in the elastic analysis, for joints of the same length, initial damage (a given stress) occurs at higher loads for the larger adhesive thicknesses due to a more uniform stress distribution along the adhesive length. This results in the joints with thicker adhesive layers having the higher predicted strengths seen in Figure 15. These features match the measured joints strengths very well and Table 2 shows good correlation between the measured and predicted strengths of the four anchor systems.

\section{CONCLUSIONS}

In this investigation, experimental, analytical and numerical results of the tensile characteristics of potted CFRP anchors have been reported. Based on this study, the following conclusions can be drawn: 
1. Different geometries of adhesively bonded anchor have been tested in tension to failure and higher failure loads were reached when either the adhesive thickness or the bonded length was higher.

2. The analytical solution developed for the adhesive stresses in the anchor was able to predict the stress state in the anchor for low values of load but not at higher loads, where the material yields. The high levels of predicted elastic stress at failure imply that nonlinear adhesive material behaviour must occur.

3. An axisymmetric FE model has been developed to assess the anchor under static tensile loading. Elastic analyses were unable to successfully predict the measured responses as the required stresses where physically unreasonable and were different for different anchor lengths.

4. Similarly, when using von Mises elasto-plasticity there was no correlation between the maximum adhesive strains at the point of failure.

5. When the adhesive was modelled with Drucker-Prager plasticity, the scatter in the adhesive failure strains, although improved, was still too high to enable reliable strength prediction to be made.

6. A cohesive zone model with progressive damage and a "frictional" post-damage region has been shown to provide predicted joint strengths that correlate closely with the measured experimental data. This model was able to successfully describe the different failure loads with different thicknesses and lengths of adhesive layer.

\section{REFERENCES}

[1] 440R-07 A. Report on Fiber-Reinforced Polymer (FRP) Reinforcement for concrete structures. ACI 2007:1-104.

[2] Mertol HC, Rizkalla SH, Scott P, Lees JM, El-Hacha R. Durability of Concrete Beams Prestressed with CFRP. ACI Spec Publ 2007;245:1-20.

[3] Schmidt JW, Täljsten B, Bennitz A, Pedersen H. FRP tendon anchorage in post-tensioned concrete structures. Concr Repair, Rehabil Retrofit 2009:1181-6.

[4] Benatar A, Gillespie JJ, Kedward K. Advanced composites manufacturing. New York: 1997.

[5] Jones RM. Mechanics of composite materials. 2n ed. New York: CRC Press; 1999.

[6] Nanni A, Bakis CE, O’Neil EF, Dixon TO. Performance of FRP tendon anchor systems for prestessing concrete structures. PCI J 1996;Jan-Feb:34-44.

[7] Schmidt JW, Bennitz A, Täljsten B, Goltermann P, Pedersen H. Mechanical anchorage of FRP tendons - A literature review. Constr Build Mater 2012;32:110-21.

[8] Bahei-El-Din YA, Dvorak GJ. New designs of adhesive joints for thick composite laminates. Compos Sci Technol 2001;61:19-40.

[9] Pincheira JA, Woyak J. Anchorage of Carbon Fiber Reinforced Polymer (CFRP) Tendons Using Cold-Swaged Sleeves. PCI J 2001; Nov-Dec:100-11.

[10] Volkersen O. Die Niet kraftverteilung in zugbeanspruchten Nietverbindungen mit konstanten Laschen querschnitten. Luftfahrtforschung 1938;15:41-7.

[11] Goland M, Reissner E. The stresses in cemented joint. J Appl Mech 1944:17-27.

[12] Tsai MY, Oplinger DW, Morton J. Improved theoretical solutions for adhesive lap joints. Int J Solids Struct 1998;35:1163-85.

[13] Smith H. Adhesive-bonded single-lap joints. NASA Langley Contract Rep NASA CR-112236 1973;January:116.

[14] Silva LF da, Neves PJ das, Adams RD, Spelt JK. Analytical models of adhesively bonded joints-Part I: Literature survey. Int J Adhes Adhes 2009;29:319-30.

[15] Silva LF da, Neves PJ das, Adams RD, Wang A, Spelt JK. Analytical models of adhesively bonded joints - Part II: Comparative study. Int J Adhes Adhes 2009;29:331-41.

[16] Crocombe AD, Ashcroft IA. Simple Lap Joint Geometry. In: Silva LF da, Ochsner A, editors. Model. Adhes. Bond. Joints, 2008, p. 3-23.

[17] Crocombe AD, Ashcroft IA. Environmental Degredation. In: Silva LF da, Ochsner A, editors. Model. Adhes. Bond. Joints, 2008, p. 225-41.

[18] Wang C. Fracture mechanics of single-fibre pull-out test. J Mater Sci 1997;32:483-90.

[19] Yue CY, Looi HC. Factors which influence the reliability of the assessment of interfacial bonding in fibrous composites using the pull-out test. Int J Adhes Adhes 2001;21:309-23.

[20] BASF Construction Chemicals BS. MBrace Primer - Product information. 2008.

[21] 440.3R-04 A. Guide Test Methods for Fiber-Reinforced Polymers (FRPs) for Reinforcing or Strengthening Concrete Structures. ACI 2004:1-40.

[22] Puigvert F, Gil L. Estudi per a l'aplicació pràctica de materials compostos d'alta capacitat portant com a elements estructurals actius. Polytechnic University of Catalonia, 2011.

[23] Crocombe AD, Richardson G, Smith PA. Measuring hydro-static dependent constitutive behaviour of adhesives using a bend specimen. J Adhes 1993;42:209-23. 
[24] Crocombe AD, Richardson G, Smith PA. A unified approach for predicting the strength of cracked and non-cracked adhesive joints. J Adhes 1995;49:211-44. 